\title{
Characterization of Diarrheagenic Escherichia coli Isolated from Fresh Beef, Pork, and Chicken Meat in Korean Markets
}

\author{
Yong Sun $\mathrm{Cho}^{1 *}$, Min Seon $\mathrm{Koo}^{1}$, and Hye Jin Jang ${ }^{2}$ \\ ${ }^{1}$ Korea Food Research Institute, Food analysis Center, Jeollabuk-do 55365, Republic of Korea \\ ${ }^{2}$ Korea Food Research Institute, Technical Assistance Center, Analysis Assistance Team, Jeollabuk-do 55365, Republic of Korea
}

Received: July 2, 2018 / Revised: August 20, 2018 / Accepted: September 15, 2019

\begin{abstract}
Diarrhea is a major public health concern associated with pathogenic Escherichia coli infections. Foodborne pathogenic $E$. coli can lead to large diarrheal outbreaks and hence, there is a need to estimate the frequency of pathogenic $E$. coli load in the various types of meat available in markets. In the present study, we classified and characterized diarrheagenic $E$. coli isolates collected from 399 raw meat samples from retail sources in Korea. Shiga toxin-producing $E$. coli (STEC) were detected in 11 (9.7\%) samples, including nine strains $(8.0 \%)$ in beef and two strains $(1.8 \%)$ in chicken. The frequency of the detected virulence markers were as follows: ast A, 28.3\%; esc V,18.6\%; eaeA,17.7\%; ent, 7.0\%; EHEC-hly, 4.4\%; stx 1, 3.5\%; and stx2, 3.5\%. We did not observe any typical EPEC, EIEC, or ETEC virulence determinants in any of the samples. The STEC serotype O26 was detected in one sample, but no other serogroups (O91, O103, 0128, 0157, O145, O111, and 0121) were found. Further research is needed to better understand the virulence mechanism of STEC serotypes, their ecology, and prevalence in animals, food, and the environment. These results will help improve risk assessment and predict the sources of food poisoning outbreaks.
\end{abstract}

Keywords: Escherichia coli, enterohemorrhagic E. coli, raw meat, multiplex PCR, O serogroup

\section{Introduction}

Escherichia coli is the predominant nonpathogenic facultative flora of the human intestine. Some E. coli strains, however, have developed the ability to cause diseases of the gastrointestinal, urinary, and central nervous system in even the human hosts with the robust immune system [1]. Diarrheagenic Escherichia coli is an important foodborne pathogen that can cause severe diarrheal symptoms. Pathogenic E. coli strains are the most common cause of pediatric diarrhea worldwide, is a major public health problem associated with high infant

\section{*Corresponding author}

Tel: +82-63-219-9242, Fax: +82-63-219-9280

E-mail:yscho@kfri.re.kr

○ 2020, The Korean Society for Microbiology and Biotechnology mortality rates, especially in developing countries [2]. Based on the expression of specific virulence determinants, diarrheagenic $E$. coli can be divided into several pathogroups including shiga toxin-producing E. coli (STEC), enterotoxigenic E. coli (ETEC), enteropathogenic $E$. coli (EPEC), enteroinvasive $E$. coli (EIEC), and enteroaggregative $E$. coli (EAEC) $[1,3]$.

STEC, also referred to as verotoxin-producing $E$. coli (VTEC), produces either or both classes of bacteriophage-encoded subunit toxins (stx1 and stx2), which are further classified into multiple subtypes. Over 1,000 serotypes of these organisms are abundant in the intestinal tracts of domestic and wild animals, and the environment [2, 4]. In addition to these genes, STEC strains often carry the adherence factor intimin coding eae gene along with other virulence genes, such as EHEC-hly, 
that code for enterohemolysin [5]. These factors facilitate bacterial adhesion and invasion into intestinal epithelial cells, leading to the formation of severe attaching-effacing (A/E) lesions. The eae gene product is the main pathogenic factor in the STEC bacteria, also known as A/E $E$. coli, that is responsible for these lesions [6, 7]. STEC is an important human pathogen in the early $1980 \mathrm{~s}$ when $E$. coli O157: H7 was linked to outbreaks, and VTEC belonging to several serotypes (O26, O145 ets.) were associated with sporadic cases of the hemolytic uremic syndrome (HUS). Highly pathogenic STEC are now known to cause large outbreaks with a wide spectrum of clinical manifestations that include diarrhea, hemorrhagic colitis, and hemolytic uremic syndrome (HUS). HUS is the leading cause of acute renal failure in children and causes significant morbidity and mortality [8]. Enterohemorrhagic E. coli (EHEC) constitutes a subgroup of STEC and can attach to the human intestinal wall to produce $\mathrm{A} / \mathrm{E}$ lesions. EHEC is considered as the principal cause of HUS [9]. The EHEC O104: H4 outbreak in Germany in the summer of 2011 demonstrated how rapidly an infectious agent could develop into a major health threat for a whole country [10]. ETEC, which is transmitted via the fecal-oral route, causes traveler's diarrhea, and diarrhea in infants through the production of heat-labile and heat-stable enterotoxins [11]. EPEC infection too leads to characteristic $\mathrm{A} / \mathrm{E}$ lesions. Depending on the presence or absence of the EPEC adherence factor (EAF) plasmid and $b f p B$ gene, EPEC is divided into typical ( $t$ EPEC) and atypical ( $a$ EPEC) subtypes [2]. The expression of the eaeA gene is a marker for EPEC infection [12]. The adhesin intimins expressed by tEPEC, aEPEC, and eae+ STEC, are antigenically heterogeneous, and at least 15 different intimin variants have been recognized in humans and cattle isolates of these bacteria. The most common intimins in human isolates are $\alpha$ (present in some tEPEC serotypes), $\beta$ (present in some tEPEC, aEPEC, and STEC serotypes), and $\gamma$ (present in some aEPEC and STEC serotypes including O157: H7) [4]. EIEC closely resembles Shigella and causes watery diarrhea and dysentery in severe cases. EIEC is transmitted via contaminated food and water. EAEC strains exhibit a typical adherence pattern in cell cultures, with cells aligning in parallel clusters akin to bricks on a wall [13-16]. EAEC has been linked to sporadic and persistent diarrhea, but detailed studies of virulence mechanisms have been hindered by the high phenotypic and genotypic diversity of this pathogroup.

$E$. coli are serotyped based on the profile of their $\mathrm{O}$ (somatic), H (flagellar), and K (capsular) surface antigens. Currently, a total of 170 different $\mathrm{O}$ antigens, each defining a serogroup, are recognized. A specific combination of $\mathrm{O}$ and $\mathrm{H}$ antigens defines the "serotype" of an isolate. $E$. coli of specific serogroups are reliably associated with certain clinical syndromes [1]. STEC, particularly O157: H7, are major foodborne pathogens. Six non 0157 serogroups, comprising of O26, O103, O111, O145, O121, and $\mathrm{O} 45$ are most frequently involved in food poisoning outbreaks [14]. Although several studies have examined the prevalence of EHEC such as E. coli O157: H7 and $\mathrm{O} 26$ in raw meat, there is limited data on the prevalence of diarrheagenic $E$. coli contamination in raw meats sold in Korea [17].

In this study, we investigated the occurrence of STEC, EPEC, ETEC, EIEC, and EAEC in raw meat samples obtained from various commercial sources in Korea by using multiplex PCR, and analyzed the patterns of virulence gene and $E$. coli $\mathrm{O}$ serotypes of identified strains to investigate the contamination level of diarrheagenic $E$. coli. Our results provide a basis for developing strategies to ensure food safety and prevent future outbreaks.

\section{Materials and Methods}

\section{Sample collection}

Raw meat samples $(\mathrm{n}=399)$ including chicken $(\mathrm{n}=$ $133)$, beef $(n=133)$, and pork $(n=133)$ were collected from butcher shops, supermarkets, and open-air markets at various locations in Korea. The samples were placed in sterile polyvinyl bags and transported to the laboratory in a cooler box containing ice blocks. The analysis was performed within $4 \mathrm{~h}$ of the sample reaching the laboratory, and the samples were maintained on ice till then.

\section{Strain isolation and identification}

$E$. coli strains in meat samples were identified by the method detailed in the Bacteriological Analytical Manual of the U.S. Food and Drug Administration (https://www.fda.gov/Food/FoodScienceResearch/LaboratoryMethods/ucm114664.htm 2018.06), with some modifications. The $25 \mathrm{~g}$ of each meat sample for 
enrichment $225 \mathrm{ml}$ of modified tryptic soy broth with novobiocin (Difco, USA) homogenized using a stomacher (400 Circulator; UK) at $260 \mathrm{rpm}$ for $1 \mathrm{~min}$, followed by incubation at $37^{\circ} \mathrm{C}$ for $18-24 \mathrm{~h}$. The enriched cultures were streaked onto two plates each of endo agar (Merck, Germany) and CHROMagar STEC (CHROMagar, France) and incubated at $37^{\circ} \mathrm{C}$ for $18 \mathrm{~h}$. At least five typical colonies were selected and analyzed by the gram staining, the catalase test, and biochemical characterization with the Vitek 2 system (bioMérieux, France).

\section{Detection of diarrheagenic $E$. coli by PCR}

$E$. coli isolates were analyzed by multiplex and gradi- ent PCR (Biometra, Germany) to detect the presence of genes encoding for virulence factors including 1) uidA, invE, esc $V$, aggR, or stx1; 2) eaeA, elt, ipaH, stx2, or estIb; and 3) pic, EHEC-hly, ent, or astA [9]. The primer pairs used for amplification were purchased from Bioneer (Korea) and are listed in Table 1. PCR was performed in a 20- $\mu$ l reaction volume containing Accupower multiplex PCR premix (Bioneer), $1 \mathrm{U}$ Taq polymerase, $250 \mu \mathrm{M}$ of each dNTP, $10 \mathrm{mM}$ Tris-HCl, $1.5 \mathrm{mM} \mathrm{MgCl}_{2}$, and 2-10 pmol of each primer and DNA extracted from single colonies was used as the template. PCR was initiated with a $30 \mathrm{~s}$ denaturation step at $98^{\circ} \mathrm{C}$, followed by over 35 cycles at $98^{\circ} \mathrm{C}$ for $30 \mathrm{~s}, 63^{\circ} \mathrm{C}$ for $60 \mathrm{~s}$, and $72^{\circ} \mathrm{C}$ for $90 \mathrm{~s}$,

Table 1. PCR primers used for the detection of virulence genes.

\begin{tabular}{|c|c|c|c|}
\hline Pathogen & Target gene & Primer sequence & Size (bp) \\
\hline \multirow[t]{6}{*}{ STEC, aEPEC ${ }^{1)}$} & eaeA & eae-F: TCAATGCAGTTCCGTTATCAGTT & 482 \\
\hline & & eae-R: GTAAAGTCCGTTACCCCAACCTG & \\
\hline & escV & MP3-escV-F: ATTCTGGCTCTCTTCTTCTTTTATGGCTG & 544 \\
\hline & & MP3-escV-R: CGTCCCCTTTTACAAACTTCATCGC & \\
\hline & ent & ent-F: TGGGCTAAAAGAAGACACACTG & 629 \\
\hline & & ent-R: CAAGCATCCTGATTATCTCACC & \\
\hline \multirow[t]{2}{*}{ tEPEC ${ }^{2)}$} & $b f p B$ & MP3-bfpB- F: GACACCTCATTGCTGAAGTCG & 910 \\
\hline & & MP3-bfpB- R: CCAGAACACCTCCGTTATGC & \\
\hline \multirow[t]{6}{*}{ EHEC } & EHEC-hly & hlyEHEC-F: TTCTGGGAAACAGTGACGCACATA & 688 \\
\hline & & hlyEHEC-R: TCACCGATCTTCTCATCCCAATG & \\
\hline & stx1 & MP4-stx1A-F: CGATGTTACGGTTTGTTACTGTGACAGC & 244 \\
\hline & & MP4-stx1A-R: AATGCCACGCTTCCCAGAATTG & \\
\hline & stx2 & MP3-stx2A-F: GTTTTGACCATCTTCGTCTGATTATTGAG & 324 \\
\hline & & MP3-stx2A- R: AGCGTAAGGCTTCTGCTGTGAC & \\
\hline \multirow[t]{4}{*}{ EIEC } & ipaH & ipaH-F: GAAAACCCTCCTGGTCCATCAGG & 437 \\
\hline & & ipaH-R: GCCGGTCAGCCACCCTCTGAGAGTAC & \\
\hline & $i n v E$ & MP2-invE-F: CGATAGATGGCGAGAAATTATATCCCG & 766 \\
\hline & & MP2-invE-R: CGATCAAGAATCCCTAACAGAAGAATCAC & \\
\hline \multirow[t]{6}{*}{ EAEC } & $\operatorname{agg} R$ & MP2-aggR-F: ACGCAGAGTTGCCTGATAAAG & 400 \\
\hline & & MP2-aggR-R: AATACAGAATCGTCAGCATCAGC & \\
\hline & pic & MP2-pic-F: AGCCGTTTCCGCAGAAGCC & 1111 \\
\hline & & MP2-pic-R: AAATGTCAGTGAACCGACGATTGG & \\
\hline & ast $A$ & MP2-astA-F: TGCCATCAACACAGTATATCCG & 102 \\
\hline & & MP2-astA-R: ACGGCTTTGTAGTCCTTCCAT & \\
\hline \multirow[t]{4}{*}{ ETEC } & elt & MP2-LT-F: GAACAGGAGGTTTCTGCGTTAGGTG & 655 \\
\hline & & MP2-LT-R: CTTTTCAATGGCTTTTTTTTTGGGAGTC & \\
\hline & estlb & MP2-STI-F: TGTCTTTTTCACCTTTCGCTC & 171 \\
\hline & & MP2-STI-R: CGGTACAAGCAGGATTACAACAC & \\
\hline \multirow[t]{2}{*}{$16 \mathrm{~s}$ rRNA } & uidA & MP2-uidA-F: ATGCCAGTCCAGCGTTTTTTGC & 1487 \\
\hline & & MP2-uidA-R: AAAGTGTGGGTCAATAATCAGGAAGTG & \\
\hline
\end{tabular}

\footnotetext{
${ }^{1)} \mathrm{aEPEC}$, atypical enteropathogenic $E$. $c$ coli, ${ }^{2)} \mathrm{tEPEC}$, typical enteropathogenic $E$. coli.
} 
and culminated with a 10 -min extension step at $72^{\circ} \mathrm{C}$. Amplified products were seperated by electrophoresis on a $2 \%$ SeaKem agarose gel (Takara Bio, Japan) at $100 \mathrm{~V}$ for $25 \mathrm{~min}$. The gel was stained with ethidium bromide $(1 \mu \mathrm{g} / \mathrm{ml})$ solution and amplicons were visualized using UV transillumination system.

\section{Serotyping}

The serotypes of STEC isolates were determined by ELISA and PCR; ELISA was performed using $E$. coli group $\mathrm{O}$ antisera (Denka Seiken, Japan) and $\mathrm{O}$ antigen was detected using the slide agglutination method according to the manufacturer's instructions. PCR was performed using primers targeting either the $r f b(\mathrm{O}$ specific polysaccharide), $w z x$ (O-unit flippase), or $w b s D$ (aminotransferase) gene present in the O-antigen biosynthetic clusters of the eight $E$. coli serogroups (O26, O157, 0145, 0111, 0121, O103, 091, and 0128) (Table $2)$. The reaction volume of $20 \mu \mathrm{l}$ contained Accupower multiplex PCR premix (Bioneer), $1 \mathrm{U}$ Taq polymerase, $250 \mu \mathrm{M}$ of each dNTP, $10 \mathrm{mM}$ Tris-HCl, $1.5 \mathrm{mM} \mathrm{MgCl}_{2}$, and 10 pmol of each primer; DNA extracted from single colonies was used as the template. PCR was initiated with a 5 -min denaturation step at $95^{\circ} \mathrm{C}$, followed by over 35 cycles at $94^{\circ} \mathrm{C}$ for $30 \mathrm{~s}, 55^{\circ} \mathrm{C}$ for $75 \mathrm{~s}$, and $68^{\circ} \mathrm{C}$ for $75 \mathrm{~s}$, and culminated with a 5 -min extension step at $68^{\circ} \mathrm{C}$ for
$7 \mathrm{~min}$. The amplified products were seperated by electrophoresis on a $1.5 \%$ SeaKem agarose gel (Takara) at $100 \mathrm{~V}$ for $25 \mathrm{~min}$. The gel was stained with ethidium bromide $(1 \mu \mathrm{g} / \mathrm{ml})$ solution and amplicons were visualized using UV transillumination system.

\section{Statistical analysis}

The isolation rates of $E$. coli were calculated with monthly positive samples per total meat samples. Seasonal patterns were analyzed by analysis of statistical program used IBM SPSS software (v.20; SPSS Inc., USA) Statistical significance was identified at $p<0.05$ and $p<0.001$, separation of the means was accomplished using the probability option (PDIFF, a pairwise t-test).

\section{Results and Discussion}

\section{Prevalence of $E$. coli in meats distributed in Korean mar- kets}

A total of $113 \mathrm{E}$. coli strains were isolated from 399 samples of three types of raw meat (pork, chicken, and beef), showing a prevalence of $28.3 \%$ (range: $7.5-59.4 \%$ ). Among the three meat types, the chicken was most frequently contaminated with $E$. coli $(79 / 133,59.4 \%)$, followed by beef $(24 / 133,18.6 \%)$ and pork (10/133, 7.5\%).

Table 2. PCR primers used for the detection of $E$. coli serogroups.

\begin{tabular}{|c|c|c|c|}
\hline Pathogen & Target gene (bp) & Primer sequence $\left(5^{\prime} \rightarrow 3^{\prime}\right)$ & Reference \\
\hline \multirow[t]{2}{*}{026} & wZX (241) & GCG CTG CAA TTG CTT ATG TA & Paddock et al. [14] \\
\hline & & TTT CCC CGC AAT TTA TTC AG & \\
\hline \multirow[t]{2}{*}{0157} & $r f b E(259)$ & CGG ACA TCC ATG TGA TAT GG & Valadez et al. [15] \\
\hline & & TTG CCT ATG TAC AGC TAA TCC & \\
\hline \multirow[t]{2}{*}{0145} & wzx (374) & TGC TCG ACT TTA CCA TCA AC & Valadez et al. [15] \\
\hline & & AAC CAA CAC CAT ACA CCT TGT CTT & \\
\hline \multirow[t]{2}{*}{0111} & $r f b(451)$ & TAG AGA AAT TAT CAA GTT AGT TCC & Paddock et al. [14] \\
\hline & & ATA GTT ATG AAC ATC TTG TTT AGC & \\
\hline \multirow[t]{2}{*}{0121} & wZX (587) & TCA TTA GCG GTA GCG AAA GG & Paddock et al. [14] \\
\hline & & TTC TGC ATC ACC AGT CCA GA & \\
\hline \multirow[t]{2}{*}{0103} & wZX (716) & TTCATCACAAGTTTCACAAG & Paddock et al. [14] \\
\hline & & CGTAATCACCTTGATTTTCT & \\
\hline \multirow[t]{2}{*}{ O91 } & $w b s D(940)$ & GATGAATCAACCTTATCGAG & Paddock et al. [14] \\
\hline & & CTGCTTATGTATAGGAATTGG & \\
\hline \multirow[t]{2}{*}{0128} & wZX (1353) & TCT TGC TTA TAG CCA GAA TT & Li et al. [25] \\
\hline & & AAT AAA CCG ACA CCG AAA & \\
\hline
\end{tabular}




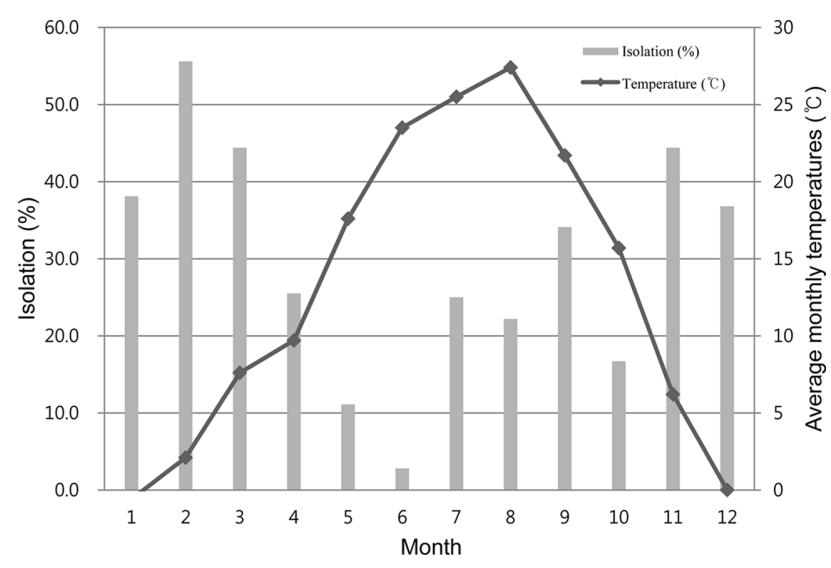

Fig. 1. Month-wise prevalence of $E$. coli isolated from raw meat samples (beef, chicken, pork) in Korea. (Average Monthly temperatures were calculated as the average air temperature at $\mathbf{4 5}$ locations in Korea, which are used to calculate the national average according to Korea Meteorological Administration)

Our results were consistent with a previous report from the U.S. (chicken, 38.7\%; beef, 19.0\%; and pork, 16.3\%) [18]. However, an earlier study in Korea found that pork meat was most contaminated with E. coli (14.9\%) [17]. The monthly prevalence of $E$. coli from January to December ranged from $2.8 \%$ to $55.6 \%$ (Fig. 1). We observed a seasonal detection pattern with higher detection rates in February and significant differences $(p>$ 0.05 ) in monthly or seasonal temperatures were determined based on the data from the Korea Meteorological Administration. The average monthly temperatures were calculated as the average air temperature at 45 locations in Korea, which are used to calculate the national average [18].

According to Lee et al. [17]: The abundance and shedding of E. coli O157: H7 in beef is independent of the season but pork sample a seasonal pattern was observed $(p>0.05)$ with higher rates compared to beef and pork in May, August and September. The prevalence of $E$. coli in four meats (chicken, turkey, pork, beef) varied during the 14 month sampling period, however no seasonality component was observed and these enteric pathogens were found in retail meats in both warm and cold months [19]. Cattle feces samples were isolated $E$. coli O157:H7 every month, the highest monthly prevalence was detected in February and the second highest peak was recorded in August. Overall, no significant differences in prevalence of $E$. coli O157:H7 [20].

The observed differences in prevalence could be due to variations in overall health and immune status of ani-

Table 3. Prevalence of virulence factors among $113 \mathrm{E}$. coli strains isolated from raw meats (beef, chicken, pork).

\begin{tabular}{|c|c|c|c|c|c|c|}
\hline \multirow{2}{*}{ Pathogen group } & \multirow{2}{*}{ Target gene } & \multicolumn{5}{|c|}{ Number of samples containing virulence marker } \\
\hline & & Beef & Chicken & Pork & Total & $\%$ \\
\hline \multirow[t]{3}{*}{ STEC, aEPEC ${ }^{1}$ ) } & $e a e A$ & 4 & 15 & 1 & 20 & 17.7 \\
\hline & escV & 5 & 15 & 1 & 21 & 18.6 \\
\hline & ent & 5 & 2 & 1 & 8 & 7.0 \\
\hline tEPEC ${ }^{2)}$ & $b f p B$ & 0 & 0 & 0 & 0 & 0 \\
\hline \multirow[t]{3}{*}{ STEC } & EHEC-hly & 5 & 0 & 0 & 5 & 4.4 \\
\hline & stx1 & 3 & 1 & 0 & 4 & 3.5 \\
\hline & $s t \times 2$ & 3 & 1 & 0 & 4 & 3.5 \\
\hline \multirow[t]{2}{*}{ EIEC } & ipaH & 0 & 0 & 0 & 0 & 0 \\
\hline & $i n v E$ & 0 & 0 & 0 & 0 & 0 \\
\hline \multirow[t]{3}{*}{ EAEC } & $\operatorname{agg} R$ & 0 & 0 & 0 & 0 & 0 \\
\hline & pic & 0 & 0 & 0 & 0 & 0 \\
\hline & ast $A$ & 3 & 26 & 3 & 32 & 28.3 \\
\hline \multirow[t]{3}{*}{ ETEC } & elt & 0 & 0 & 0 & 0 & 0 \\
\hline & estla & 0 & 0 & 0 & 0 & 0 \\
\hline & estlb & 0 & 0 & 0 & 0 & 0 \\
\hline E. coli & uidA & 21 & 74 & 9 & 104 & 92 \\
\hline
\end{tabular}

1)aEPEC, atypical enteropathogenic $E$. coli, ${ }^{2)} \mathrm{tEPEC}$, typical enteropathogenic $E$. coli. 
mals selected for sampling as well as farm management practices [21]. In addition, meat products that are sold or cut according to the buyer's request may become crosscontaminated by direct transmission of enteric pathogens, which can be avoided by hygienic handling practices.

\section{Presence of virulence gene determinants}

Multiplex PCR was used to detect virulence genes harbored by diarrheagenic $E$. coli and the strains were classified as STEC, EPEC, ETEC, EIEC, or EAEC. Virulence genes were detected in $47.8 \%$ (54/113) of isolated $E$. coli strains: $49.4 \%$ (39/79) in chicken, $45.8 \%$ (11/ $24)$ in beef, and $40 \%(4 / 10)$ in pork samples. The most common virulence marker was ast $A(28.3 \%)$, followed by escV (18.6\%), eaeA (17.7\%), and ent (7.0\%). Interestingly, pathogenic genes were detected at a significantly high frequency in chicken samples (Table 3 ). Since $E$. coli is a common microorganism present in the intestines of animals, chicken is considered to have the highest detection rate because the whole carcass is produced, processed and distributed [20].

We used the following criteria to determine $E$. coli pathogen groups [1,22]. For STEC, we evaluated the presence of stx 1 and/or stx 2 and possibly eaeA, escV, ent, and EHEC-hly; for EPEC, eaeA and possibly esc $V$ and $b f p B$ (with the absence of $b f p B$ indicating aEPEC); for ETEC, elt and/or estla or estlb; for EIEC, invE and ipaH; and for EAEC, aggR or a combination of at least two of the three astA, aggR, and pic genes (EAEC marker genes). Of the 54 samples diarrheagenic $E$. coli, EAEC is 25 samples, STEC/EPEC is 22 samples and 7 samples harbored STEC and EAEC markers; and no typical EPEC, EIEC, or ETEC virulence determinants were detected in any of the samples. Several samples contained two or more virulence markers but only aEPEC and STEC were detected (Table 4). Two samples were negative for eaeA but positive for esc $V$ and ent, indicating the presence of EPEC. Although the astA gene was detected at a high frequency in this study, we did not detect the $\operatorname{agg} R$ gene and were, therefore, unable to classify the isolates as EAEC. However, astA was simultaneously isolated from six $a$ EPEC and one STEC strain. STEC was detected in 11 (9.7\%) samples: nine strains (8.0\%) in beef, two (1.8\%) in chicken, and none in pork samples (Table 5). These rates are slightly higher than those observed in other countries; STEC was detected in $4 \%$ of beef samples in France, $3 \%$ of raw beef samples in Australia, and $1.75 \%$ of minced beef samples in Switzerland [23]. A higher frequency of STEC has also been reported for beef sampled in Korea [17]. The discrepancies in the contamination level may be due to variations in the meat source and processing environment as well as methodological differences such as the number of samples and sample test period [24, 25]. Contamination can also occur during the processing of slaughtered animals at abattoirs and subsequently amplified by improper storage, handling, or cooking, especially in the case of ground meat [16].

\section{Virulence genes and serotyping of isolated STEC}

The genetic profiles of the 11 STEC strains were determined according to the presence of virulence markers such as vero cytotoxin (stx1 and/or stx2) and/or EHEChly. The serotypes (O26, O157, O145, 0111, 0121, O103, O91, and O128) of eight STEC strains were determined by PCR. Serotype O26 was detected in one sample of beef, while another could not be typed. O26 was also detected in the $E$. coli $\mathrm{O}$ antisera analysis. The serotypes $\mathrm{O} 115$ and $\mathrm{O} 1$ were detected in beef and chicken samples, respectively, whereas the serotype of other strains could not be determined (Table 5). O26 and O111 serogroups can be pathogenic and are more prominent than 0157 : $\mathrm{H} 7$ in many countries [2]. It is widely accepted that

Table 4. Prevalence of diarrheagenic E. coli among 113 E. coli strains isolated from raw meats (beef, chicken, pork).

\begin{tabular}{|c|c|c|c|c|c|c|c|c|}
\hline \multirow{3}{*}{$\begin{array}{l}\text { Pathogen } \\
\text { group }\end{array}$} & \multicolumn{8}{|c|}{ Samples } \\
\hline & \multicolumn{2}{|c|}{ Beef } & \multicolumn{2}{|c|}{ Chicken } & \multicolumn{2}{|c|}{ Pork } & \multicolumn{2}{|c|}{ Total } \\
\hline & No. & $\%$ & No. & $\%$ & No. & $\%$ & No. & $\%$ \\
\hline $\mathrm{aEPEC} C^{1)}$ & 0 & 0.0 & 17 & 15.0 & 1 & 0.9 & 18 & 15.9 \\
\hline STEC & 9 & 8.0 & 2 & 1.8 & 0 & 0.0 & 11 & 9.8 \\
\hline Total & 9 & 8.0 & 19 & 16.8 & 1 & 0.9 & 29 & 25.7 \\
\hline
\end{tabular}

1)aEPEC, atypical enteropathogenic E. coli. 
Table 5. $O$ antigen serotyping of isolated Shiga toxin-producing $E$. coli strains.

\begin{tabular}{|c|c|c|c|}
\hline Sample & Virulence gene & PCR serotype & O antigen serotype \\
\hline Beef & eaeA/escv/ent/EHEC-hly/uidA & & $1-4$ poly \\
\hline Beef & escv/ent/EHEC-hly/stx1/uidA & $\mathrm{O} 26$ & $\mathrm{O} 26$ \\
\hline Beef & stx1/uidA & & \\
\hline Beef & stx2/astA/uidA & & \\
\hline Beef & eaeA/eaeA/escv/ent/EHEC-hly/uidA & & 0115 \\
\hline Beef & eaeA/eaeA/escv/ent/EHEC-hly/stx1/uidA & & \\
\hline Beef & stx2/uidA & & \\
\hline Beef & eaeA/escv/ent/eaeA/EHEC-hly/uidA & & \\
\hline Beef & stx2/astA/uidA & & \\
\hline Chicken & stx2/uidA & & \\
\hline Chicken & stx1/uidA & & 01 \\
\hline
\end{tabular}

based on antigen analysis of different serogroups, serotyping can be used to evaluate the pathogenicity of $E$. coli. However, this involves laborious agglutination reactions using antisera raised against $\mathrm{O}$ reference strains. In addition, cross-reaction among different serogroups may yield inconsistent results. Earlier, independent studies have suggested that the stx gene may not represent a human type of O26, O103, O111, O145, and 0157 serotypes [8, 26]. Therefore, strains belonging to the O26, O103, O111, O145, and O157 serotypes may pose the highest risk of human infection. Moreover, there is increasing evidence that different $\mathrm{O}$ serogroups of STEC do not harbor the stx gene and therefore do not produce shiga toxin. Both, toxigenic (stx-positive) and non-toxigenic (stx-negative) strains, are likely to coexist within each O serogroup [15]. Non-toxigenic O26 and O157 variants are not of significant concern in terms of food safety/public health. However, occasionally, stx-negative $E$. coli have been isolated from human clinical samples. The st $x$-negative, eae-positive $\mathrm{O} 26$ is likely to be atypical EPEC that is rarely associated with severe outbreaks of human diarrheal disease [27]. The detection of both stx and $\mathrm{O}$-serogroup gene sequences in foods indicates the presence of a pathogenic $E$. coli strain. These results warrant further research to better understand the virulence mechanism of STEC, their ecology, and prevalence in animals, and food, and environment.

In summary, our results demonstrate that raw meats sold in Korea have a significant risk of becoming contaminated with pathogenic $E$. coli during processing. Therefore, it is essential not only to wash meat before preparation to reduce the risk of cross-contaminating the food preparation area but also to properly cook the meat at an appropriate temperature which can effectively destroy pathogenic $E$. coli cells to prevent human infection. These findings underscore the need for vigilance in observing basic hygiene and safety practices during the handling of meat products.

\section{Acknowledgments}

This research was supported by Main Research Program of the Korea Food Research Institute (KFRI) funded by the Ministry of Science, ICT \& Future Planning.

\section{Conflict of Interest}

The authors have no financial conflicts of interest to declare.

\section{References}

1. Kaper, JB, Nataro JP, Mobley HL. 2004. Pathogenic Escherichia coli. Nat. Rev. Microbiol. 2: 123-140.

2. Kagambega, A, Martikainen O, Lienemann T, Siitonen A, Traoré AS, Barro N, et al. 2012. Diarrheagenic Escherichia coli detected by 16-plex PCR in raw meat and beef intestines sold at local markets in Ouagadougou, Burkina Faso. Int. J. Food Microbiol. 153: 154158.

3. López-Saucedo C, Cerna JF, Villegas-Sepulveda N, Thompson R, Velazquez FR, Torres J, et al. 2003. Single multiplex polymerase chain reaction to detect diverse loci associated with diarrheagenic Escherichia coli. Emerg. Infect. Dis. 9: 127-131.

4. Karmali MA. 2018. Factors in the emergence of serious human infections associated with highly pathogenic strains of Shiga toxin-producing Escherichia coli. Int. J. Med. Microbiol. 8: 1067- 
1072.

5. Schmidt H, Beutin L, Karch H. 1995. Molecular analysis of the plasmid-encoded hemolysin of Escherichia coli O157: H7 strain EDL 933. Infect. Immun. 63: 1055-1061.

6. Ranjbar R, Dehkordi FS, Shahreza MHS, Rahimi E. 2018. Prevalence, identification of virulence factors, O-serogroups and antibiotic resistance properties of Shiga-toxin producing Escherichia coli strains isolated from raw milk and traditional dairy products. Antimicrob. Resist. Infect. Control. 7: 53.

7. Wang J, Stanford K, McAllister TA, Johnson RP, Chen J, Hou H, et al. 2016. Biofilm formation, virulence gene profiles, and antimicrobial resistance of nine serogroups of non-0157 Shiga toxinproducing Escherichia coli. Foodborne Pathog. Dis. 13: 316-324.

8. Paton JC, Paton AW. 1998. Pathogenesis and diagnosis of Shiga toxin-producing Escherichia coli infections. Clin. Microbiol. Rev. 11: 450-479.

9. Dini C, De Urraza P. 2010. Isolation and selection of coliphages as potential biocontrol agents of enterohemorrhagic and Shiga toxin-producing E. coli (EHEC and STEC) in cattle. J. Appl. Microbiol. 109: 873-887.

10. Burger R. 2012. EHEC 0104:H4 in Germany: Large outbreak of bloody diarrhea and haemolytic uraemic syndrome by Shiga toxin-producing E. coli via contaminated food, pp. 115-130. In: Institute of Medicine (USA). Improving Food Safety Through a One Health Approach: Workshop Summary. National Academies Press, Washington D.C.

11. Barrett TJ, Kaper JB, Jerse AE, Wachsmuth IK. 1992. Virulence factors in Shiga-like toxin-producing Escherichia coli isolated from humans and cattle. J. Infect. Dis. 165: 979-980.

12. Bischoff C, Lüthy J, Altwegg M, Baggi F. 2005. Rapid detection of diarrheagenic E. coli by real-time PCR. J. Microbiol. Methods. 61: 335-341.

13. Badri S, Filliol I, Carle I, Hassar M, Fassouane A, Cohen N. 2009. Prevalence of virulence genes in Escherichia coli isolated from food in Casablanca (Morocco). Food Control. 20: 560-564.

14. Paddock Z, Shi X, Bai J, Nagaraja TG. 2012. Applicability of a multiplex PCR to detect O26, O45, 0103, 0111, 0121, 0145, and O157 serogroups of Escherichia coli in cattle feces. Vet. Microbiol. 156: 381-388.

15. Perelle S, Dilasser F, Grout J, Fach P. 2007. Screening food raw materials for the presence of the world's most frequent clinical cases of Shiga toxin-encoding Escherichia coli O26, 0103, 0111, 0145, and 0157. Int. J. Food Microbiol. 113: 284-288.

16. Valadez AM, Debroy C, Dudley E, Cutter CN. 2011. Multiplex PCR detection of Shiga toxin-producing Escherichia coli strains belonging to serogroups $0157,0103,091,0113,0145,0111$, and $\mathrm{O} 26$ experimentally inoculated in beef carcass swabs, beef trim, and ground beef. J. Food Prot. 74: 228-239.

17. Lee GY, Jang HI, Hwang IG, Rhee MS. 2009. Prevalence and classification of pathogenic Escherichia coli isolated from fresh beef, poultry, and pork in Korea. Int. J. Food Microbiol. 134: 196-200.

18. https://data.kma.go.kr/stcs/grnd/grndTaList.do?pgmNo=70 (Accessed Jan. 3, 2020)

19. Zhao C, Ge B, De Villena J, Sudler R, Yeh E, Zhao S, et al. 2001. Prevalence of Campylobacter spp., Escherichia coli, and Salmonella serovars in retail chicken, turkey, pork, and beef from the Greater Washington, D.C., area. Appl. Environ. Microbiol. 67: 54315436.

20. Alam M, Zurek L. 2006. Seasonal prevalence of Escherichia coli 0157: H7 in beef cattle feces. J. Food Prot. 69: 3018-3020.

21. Pervez A, Anjum FR, Bukhari AA, Anam S, Arshad MI. 2018. Isolation and virulence genes characterization of diarrheagenic Escherichia coli from calves. Pak. Vet. J. 38: 133-136.

22. Müller D, Greune L, Heusipp G, Karch H, Fruth A, Tschäpe $H$, et al. 2007. Identification of unconventional intestinal pathogenic Escherichia coli isolates expressing intermediate virulence factor profiles by using a novel single-step multiplex PCR. Appl. Environ. Microbiol. 73: 3380-3390.

23. Xia X, Meng J, McDermott PF, Ayers A, Blickenstaff K, Tran TT, et al. 2010. Presence and characterization of Shiga toxin-producing Escherichia coli and other potentially diarrheagenic E. coli strains in retail meats. Appl. Environ. Microbiol. 76: 1709-1717.

24. Han W, Liu B, Cao B, Beutin L, Krüger U, Liu H, et al. 2007. DNA microarray-based identification of serogroups and virulence gene patterns of Escherichia coli isolates associated with porcine postweaning diarrhea and edema disease. Appl. Environ. Microbiol. 73: 4082-4088.

25. Kegode RB, Doetkott DK, Khaitsa ML, Wesley IV. 2008. Occurrence of Campylobacter species, Salmonella species and generic Escherichia coli in meat products from retail outlets in the Fargo metropolitan area. J. Food Safety 28: 111-125.

26. Li Y, Liu D, Cao B, Han W, Liu Y, Liu F, et al. 2006. Development of a serotype-specific DNA microarray for identification of some Shigella and pathogenic Escherichia coli strains. J. Clin. Microbiol. 4: 4376-4383.

27. Jaros $\mathrm{P}$, Cookson $\mathrm{A}$, Reynolds $\mathrm{A}$, Withers $\mathrm{H}$, Clemens R, Brightwell $G$, et al. 2008. The effect of transportation and lairage on faecal shedding and carcass contamination with Escherichia coli 0157 and 026 in very young calves in New Zealand. Epidemiol. Infect. 146: $1089-1100$. 